\title{
Mandibular first and second premolars with challenging root canal anatomy - Part 1: Review of the literature
}

SADJ April 2020, Vol. 75 No. 3 p 126 - p129

PJ Van der Vyver ${ }^{1}$, M Vorster ${ }^{2}$, CH Jonker ${ }^{3}$

\section{INTRODUCTION (Part 1)}

Mandibular premolars can be one of the most difficult teeth to treat endodontically because of the variations in root canal anatomy. ${ }^{1,2}$

According to England, Hartwell and Lance, ${ }^{3}$ variation in root canal anatomy is one of the main reasons why mandibular premolars have a high frequency of failures and flare-ups. The literature indicates that the incidence of the number of roots and the number of canals varies greatly in human teeth. ${ }^{4,5}$

\section{MANDIBULAR FIRST PREMOLARS}

Mandibular first premolars can present with an extremely complex internal root canal morphology. 6,7 A study by the University of Washington showed mandibular first premolars to have the highest failure rate when evaluating non-surgical root canal therapy, with a reported failure rate of $11.4 \% .^{8}$

This high incidence of failure could be attributed to the high incidence of variations in these teeth and the difficulty of negotiating, shaping and cleaning these canals if present. Age, sex and ethnicity are some of the factors that contribute to the variations in canal configurations between different studies. ${ }^{9-11}$

According to Cleghorn, Christie and Dong, ${ }^{12}$ who reported on eight anatomical studies that include 4462 teeth, most mandibular first premolars have a single root with a single root canal (97.9\%) (Figure 1).

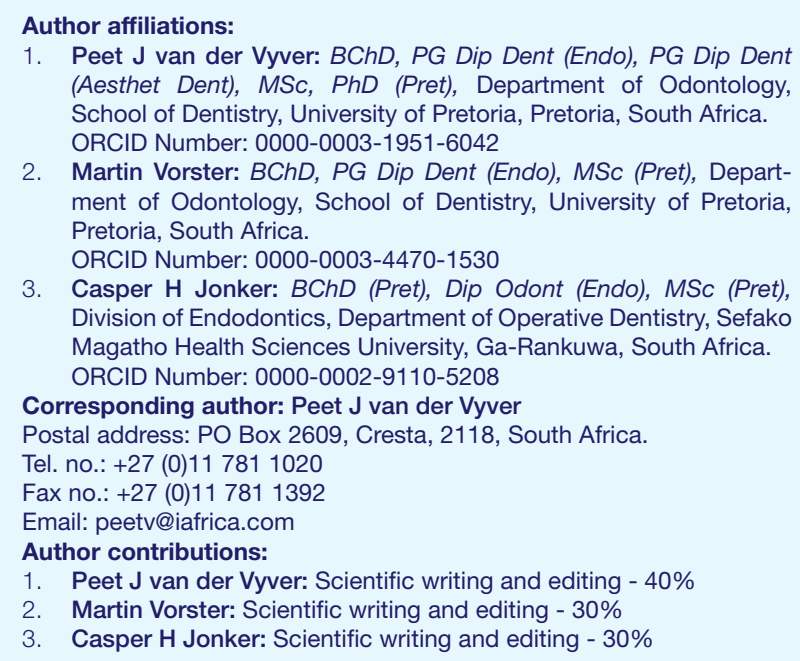

1. Peet J van der Vyver: BChD, PG Dip Dent (Endo), PG Dip Dent (Aesthet Dent), MSc, PhD (Pret), Department of Odontology, School of Dentistry, University of Pretoria, Pretoria, South Africa. ORCID Number: 0000-0003-1951-6042

2. Martin Vorster: BChD, PG Dip Dent (Endo), MSc (Pret), Department of Odontology, School of Dentistry, University of Pretoria, Pretoria, South Africa.

ORCID Number: 0000-0003-4470-1530

3. Casper H Jonker: BChD (Pret), Dip Odont (Endo), MSc (Pret), Division of Endodontics, Department of Operative Dentistry, Sefako Magatho Health Sciences University, Ga-Rankuwa, South Africa. ORCID Number: 0000-0002-9110-5208

Corresponding author: Peet $\mathrm{J}$ van der Vyver

Postal address: PO Box 2609, Cresta, 2118, South Africa.

Tel. no.: +27 (0) 117811020

Fax no.: +27 (0)117811392

Email: peetv@iafrica.com

Author contributions:

1. Peet J van der Vyver: Scientific writing and editing - $40 \%$

2. Martin Vorster: Scientific writing and editing - $30 \%$

3. Casper $\mathrm{H}$ Jonker: Scientific writing and editing - $30 \%$

Vertucci ${ }^{4}$ shows that a single canal is found in $70 \%$ of cases; in $4 \%$ of cases there could be two canals joining at a common apical foramen (Figure 2); in $24 \%$ of cases one root canal bifurcates at the apical third of the root into two branches (Figure 3); and in $1.5 \%$ of cases there could be two independent canals (Figure 4).

In 1990, Hülsmann ${ }^{13}$ reported a mandibular first premolar with three root canals and, according to Baisden, Kulild and Weller, ${ }^{14}$ this tooth can also present with a C-shaped root canal.
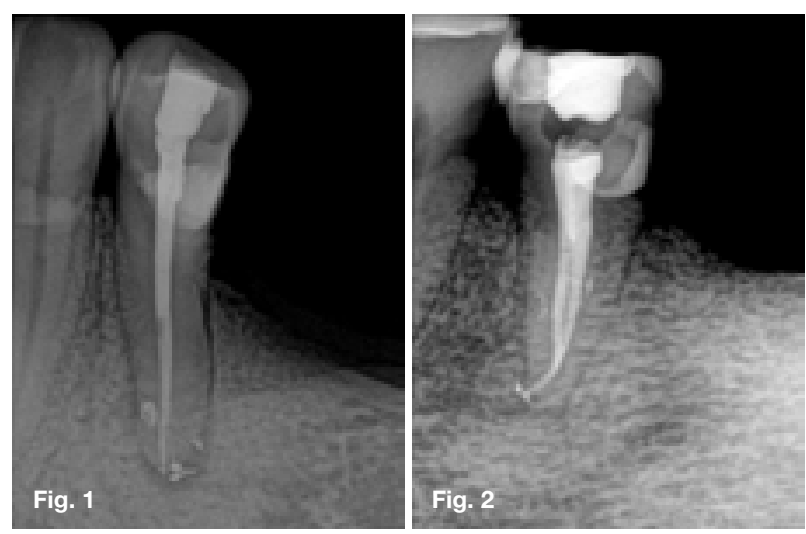

Figure 1. Periapical radiograph of a mandibular left first premolar with a single canal. Note the multiple portals of exit that are visible after irrigation and obturation.

Figure 2. Periapical radiograph of a mandibular left first premolar with two root canal systems joining in the apical third into a single canal. Note the midroot lateral canals that are visible after irrigation and obturation.

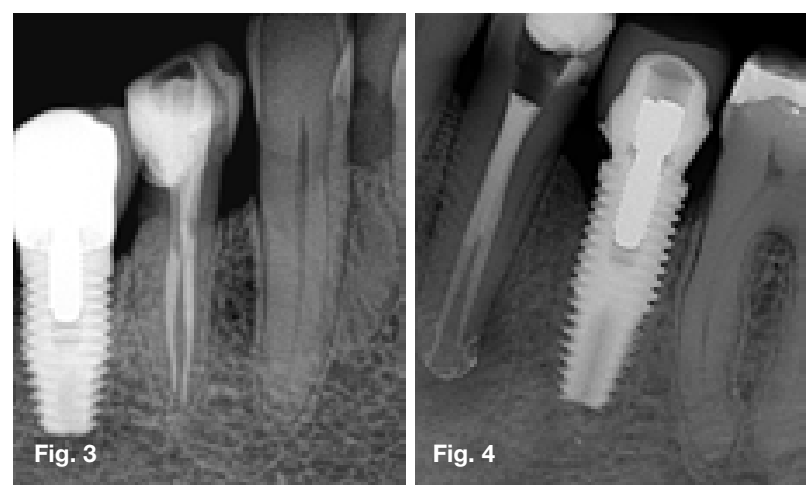

Figure 3. Periapical radiograph of a mandibular right first premolar with two independent root canals in one root.

Figure 4. Periapical radiograph of a mandibular right first premolar with a root canal system that bifurcates into two branches at the junction between the midroot and apical third of the root. 
A review by Cleghorn, Christie and Dong ${ }^{12}$ reports on the internal morphology of 4733 mandibular first premolar teeth. One canal was present in $75.8 \%$ of the teeth studied, compared to $24.2 \%$ of teeth having two or more canals.

A single apical foramen was found in $78.9 \%$ of teeth, whereas two or more apical foramina were found in $21.1 \%$ of teeth. They also reported that mandibular first premolars with two roots were found in $1.8 \%$ of cases and that three-rooted (0.2\%) and four-routed $(<0.1 \%)$ varieties were quite rare.

\section{MANDIBULAR SECOND PREMOLARS}

The mandibular second premolar usually has one root with a single root canal system that can occur in $65 \%$ to $100 \%$ of cases $4,7,12,15,16$ (Figure 5). A review of the literature on root configuration of mandibular second premolars when 4019 teeth were assessed showed a $99.6 \%$ incidence of single-rooted teeth. ${ }^{12}$

The single root can also present with two canals in $1-11 \%^{12,17,18}$ with a single apical foramen in $91.8 \%$ (Figure 6 ), or two or more apical foramina in $8.2 \%$ of cases (Figure 7). ${ }^{12}$

Several authors have also reported single roots with three root canals in approximately $0.4 \%$ of cases (Figures 8A-E). ${ }^{18-21}$

Rhodes $^{22}$ and Macri and Zwemer ${ }^{23}$ have reported mandibular second premolars with four and five root canals respectively. According to a literature review by Cleghorn, Christie and Dong, ${ }^{12}$ mandibular second premolars can have two separate roots in $0.3 \%$ of cases (Figure 10) and three separate roots in $0.1 \%$ of cases (Figure 11).
Although normal root canal anatomy and canal configuration are well documented in the literature, ${ }^{8}$ there are still large variations in data on anomalies and the incidence thereof. ${ }^{12}$

Similar findings are reported by Park et al. ${ }^{24}$ These authors report an incidence of $0.6 \%$ of mandibular second premolars presenting with two separate roots. According to Sachdeva et al. ${ }^{25}$ an investigation of available literature revealed no cases of four separate roots and four distinct root canals in mandibular second pre-molars.

It is important to note that the root and canal morphology of the second mandibular premolar can be influenced by gender, age and ethnicity. ${ }^{26-28}$ Park et al. ${ }^{24}$ and co-workers conclude in their study that no significant differences could be found between female and male patients or between left and right sides of the mandibula.

Tzanetakis et al. ${ }^{29}$ report a unique case of a mandibular second premolar with four canals diagnosed and treated with the use of the dental operating microscope, emphasising the vital role of proper magnification in diagnosis and treatment of challenging anatomy. The use of conventional radiographs provides limited information; investigation using specialised radiographic techniques in conjunction with traditional two-dimensional images is advocated to confirm challenging anatomy. ${ }^{25}$

In part two of this article the authors will provide the clinician with guidelines and clinical techniques that might aid in root canal treatment on mandibular premolars that present with unusual root canal anatomy.
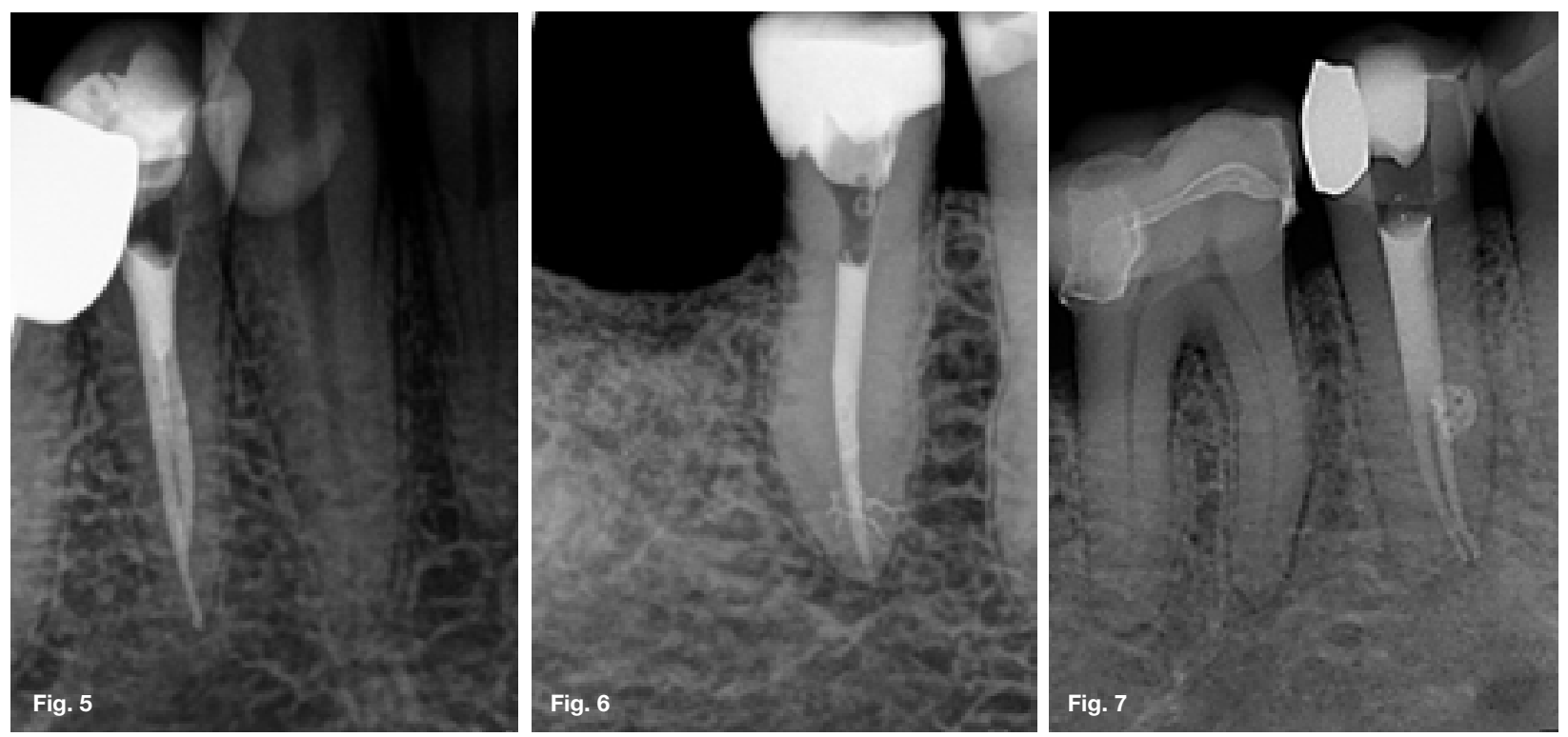

Figure 5. Periapical radiograph of a mandibular right second premolar with a single root with two separate root canal systems joining in the apical third of the root to form one apical foramen.

Figure 6. Periapical radiograph of a mandibular right second premolar with a single canal. Note the multiple ports of exit that are visible after irrigation and obturation.
Figure 7. Periapical radiograph of a mandibular right second premolar with a single root and two separate root canal systems with two apical foramina. Note the midroot lateral portal of exit that is visible after irrigation and obturation. 

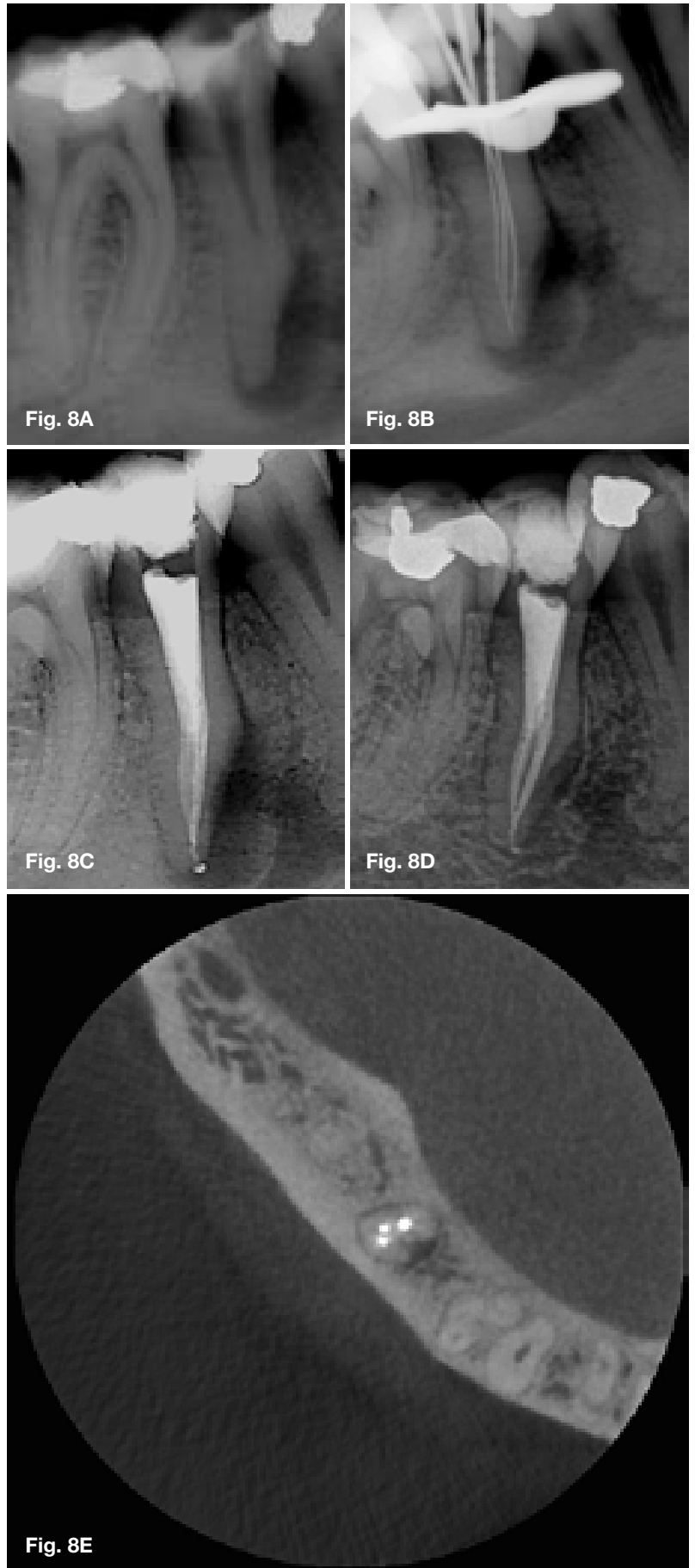

\section{Figure 8.}

(A). Periapical radiograph of a mandibular right second premolar with a single root with a large periapical radiolucency.

(B). Three root-canal systems were located, joining in the apical third to end in one apical foramen.

(C). Obturation of the three root-canal systems.

(D). Periapical radiograph after six months showing good healing of the periapical pathology.

(E). Axial slice of a 6-month follow-up CBCT 3mm from the apex showing the three separate root canals.

\section{References}

1. Slowey R. Root canal anatomy: road map to successful endodontics. Dent Clin North Am. 1979; 23: 555 -73.

2. El Deeb ME. Three root canals in mandibular second premolars: literature review and a case report. J Endod. 1982; 8(8): $376-7$.

3. England Jr MC, Hartwell GR, Lance JR. Detection and treatment of multiple canals in mandibular premolars. $J$ Endod. 1991; 17(4): 174-8.

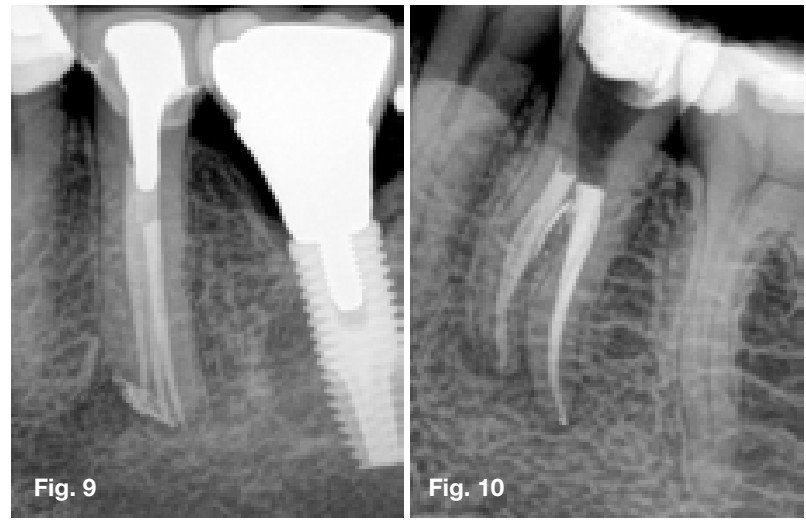

Figure 9. Periapical radiograph of a mandibular left second premolar with a single root and 3 separate root-canal systems ending in three apical foramina.

Figure 10. Periapical radiograph of a mandibular left second premolar with two separate roots and root canals.
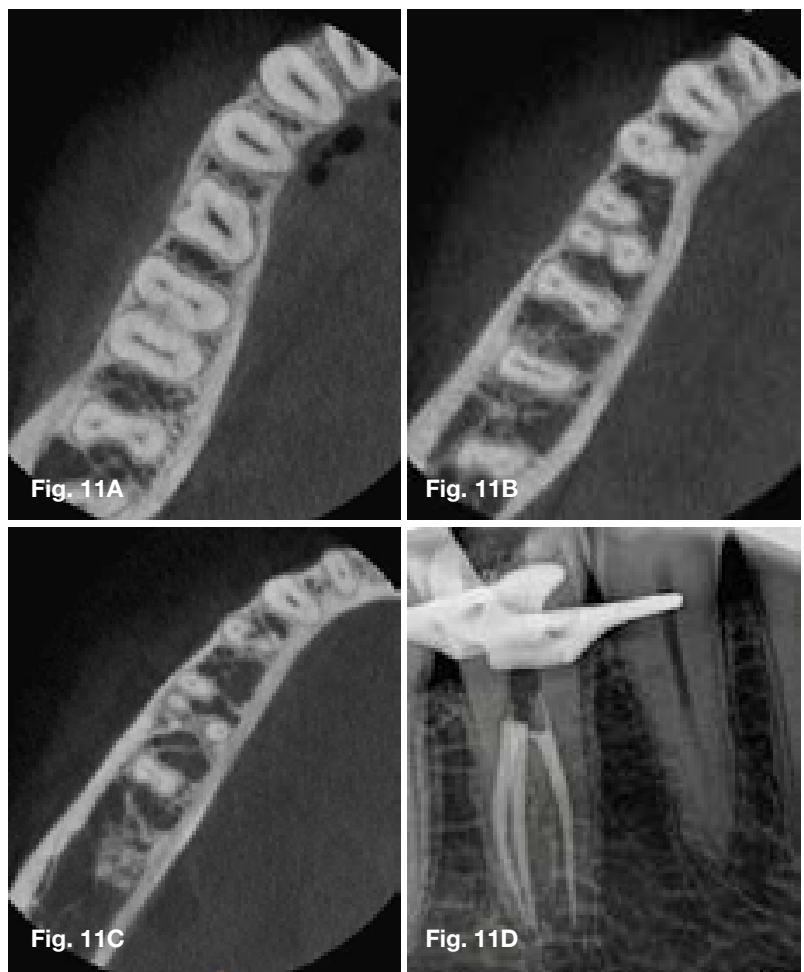

Figure 11.

(A). Axial slice of a CBCT scan through the coronal aspect (DEJ level) of a non-vital mandibular right second premolar showing an irregularly shaped root;

(B). Axial slice of a CBCT scan through the midroot aspect depicting three separate roots and root canals;

(C). Axial slice of a CBCT scan through the apical level showing three separate roots and root canals;

(D). Post-operative periapical radiograph illustrating the final result after root canal preparation and obturation (courtesy of Dr M du Bruyn).

4. Vertucci FJ. Root canal morphology of mandibular premolars. J Am Dent Assoc. 1978; 97(1): 47-50.

5. Jordan RE, Abrams L, Kraus BS. Kraus' dental anatomy and occlusion: Mosby Year Book; 1992.

6. Walton RE, Torabinejad M. Principles and practice of endodontics: Saunders; 1996.

7. Ash MM, Nelson SJ. Wheeler's dental anatomy, physiology, and occlusion $8^{\text {th }}$ Edition: Saunders; 2003. 
8. Ingle JI, Baumgartner JC. Ingle's endodontics 6: PMPH -USA; 2008.

9. Trope M, Elfenbein L, Tronstad L. Mandibular premolars with more than one root canal in different race groups. J Endod. 1986; 12(8): 343-5.

10. Pineda F. Roentgenographic investigation of the mesiobuccal root of the maxillary first molar. Oral Surg, Oral Med, Oral Pathol. 1973; 36(2): 253-60.

11. Sert S, Bayirli GS. Evaluation of the root canal configurations of the mandibular and maxillary permanent teeth by gender in the Turkish population. J Endod. 2004; 30(6): 391-8.

12. Cleghorn BM, Christie WH, Dong CC. The root and root canal morphology of the human mandibular second premolar: A literature review. J Endod. 2007; 33(9): 1031-7.

13. Hülsmann M. Mandibular first premolar with three root canals. Dent Traumatol. 1990; 6(4): 189-91.

14. Baisden MK, Kulild JC, Weller RN. Root canal configuration of the mandibular first premolar. J Endod. 1992; 18(10): $505-8$

15. Vertucci FJ. Root canal anatomy of the human permanent teeth. Oral surg, Oral Med, and Oral Pathol. 1984 58(5): 589-99.

16. Rodig T, Hulsmann M. Diagnosis and root canal treatment of a mandibular second premolar with three root canals. Int Endod J. 2003; 36(12): 912-9.

17. Pineda F, Kuttler Y. Mesiodistal and buccolingual roentgenographic investigation of 7,275 root canals. Oral Surg, Oral Med, and Oral Pathol. 1972; 33(1): 101-10.

18. Zillich R, Dowson J. Root canal morphology of mandibular first and second premolars. Oral Surg, Oral Med, and Oral Pathol. 1973; 36(5): $738-44$

19. El Deeb ME. Three root canals in mandibular second premolars: literature review and a case report. J Endod. 1982; 8(8): $376-7$
20. Singh RP, Stamps HF, Tatum RC. Endodontic considerations of a tricanaled mandibular second premolar: case report and literature review. J Md State Dent Assoc. 1987; 30(1): 13-6

21. Fischer GM, Evans CE. A three-rooted mandibular second premolar. Gen Dent. 1992; 40(2): 139-40.

22. Rhodes JS. A case of unusual anatomy: a mandibular second premolar with four canals. Int Endod J. 2001; 34(8): $645-8$.

23. Macri E, Zmener O. Five canals in a mandibular second premolar. J Endod. 2000; 26(5): 304-5.

24. Park JB, Kim N, Park S, Kim Y, Ko Y. Evaluation of root anatomy of permanent mandibular premolars and molars in a Korean population with cone-beam computed tomography. Eur J Dent. 2013; 7(1): 94-101.

25. Sachdeva GS, Ballal S, Gopikrishna V, Kandaswamy D. Endodontic management of a mandibular second premolar with four roots and four root canals with the aid of spiral computed tomography: a case report. J Endod. 2008; 34(1): $104-7$

26. Ross IF, Evanchik PA. Root fusion in molars: incidence and sex linkage. J Periodontol. Nov 1981; 52(11): 663-7.

27. Walker RT. Root canal anatomy of mandibular first premolars in a southern Chinese population. Endod Dent Traumatol. 1988; 4(5): $226-8$.

28. Awawdeh LA, Al-Qudah AA. Root form and canal morphology of mandibular premolars in a Jordanian population. Int Endod J. 2008; 41(3): 240-8.

29. Tzanetakis GN, Lagoudakos TA, Kontakiotis EG. Endodontic treatment of a mandibular second premolar with four canals using operating microscope. J Endod. 2007; 33(3): 318-21.

\section{Do the CPD questionnaire on page 161}

The Continuous Professional Development (CPD) section provides for twenty general questions and five ethics questions. The section provides members with a valuable source of CPD points whilst also achieving the objective of CPD, to assure continuing education. The importance of continuing professional development should not be underestimated, it is a career-long obligation for practicing professionals.

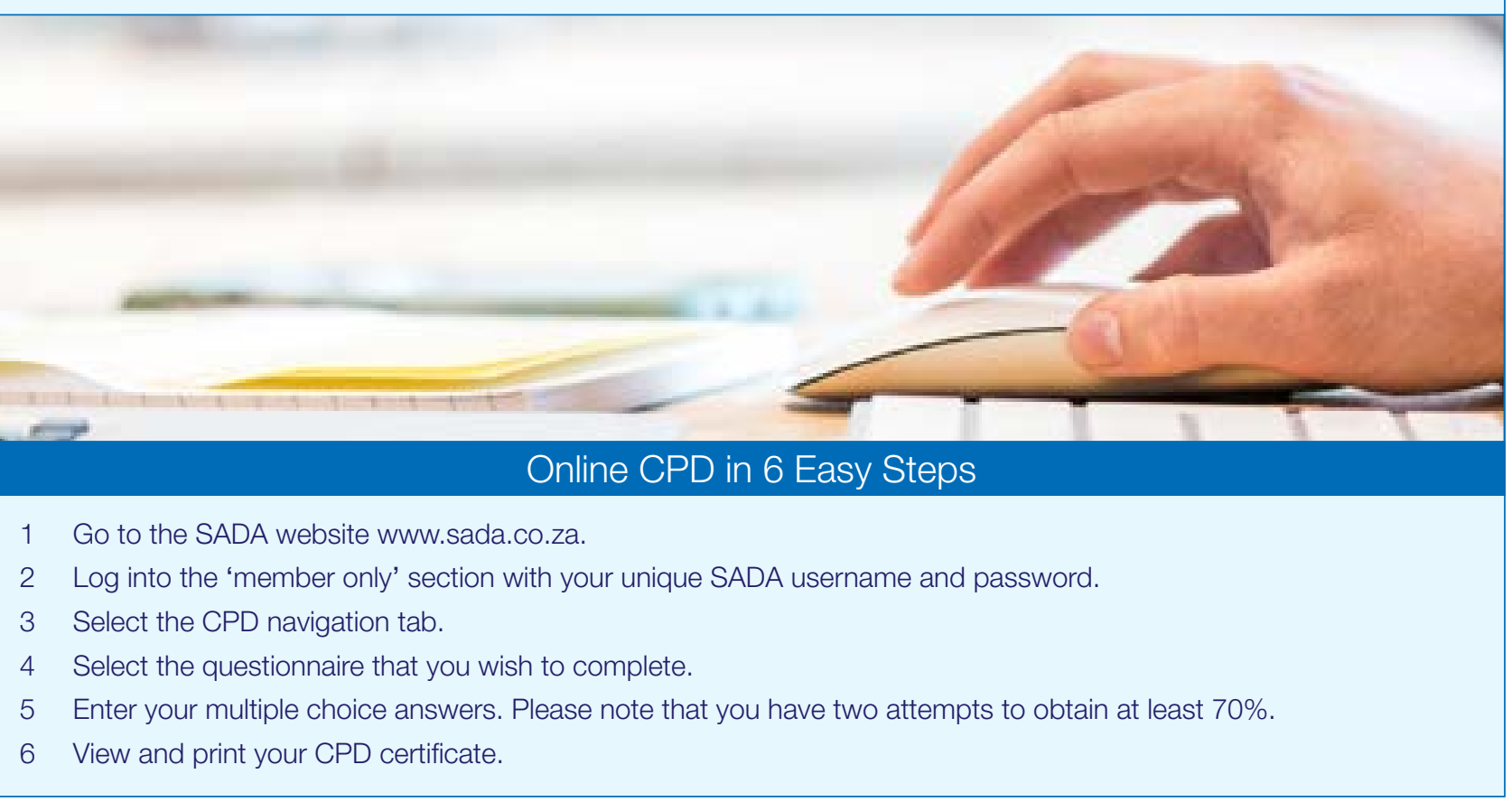

